\title{
ERP Software Evaluation and Comparative Analysis
}

\author{
Krešimir Fertalj and Damir Kalpić \\ Faculty of Electrical Engineering and Computing, University of Zagreb, Croatia
}

\begin{abstract}
This paper presents the results of an investigation performed in 2001 under the title Comparative Analysis of Information Systems Software in Croatia. The focus was set on the comparative analysis of domestic and foreign Enterprise Resource Planning (ERP) software, which is present in Croatia. The investigation was performed from the standpoint of ERP applicability, regardless of the development methods and information technology. In other words, the evaluation was performed primarily from the standpoint of users rather than designers, programmers or other persons engaged in the system development and implementation.
\end{abstract}

System evaluation was performed in several phases and in multiple steps. A general list of relevant ERP characteristics was established first. This initial list was updated in co-operation with ERP suppliers and users. They completed the list by adding the characteristics they regarded as important or accentuated some features of their solutions that had not been mentioned initially. System evaluation was performed at the users' sites, having insight to real applications. To increase the objectivity and accuracy, the evaluating teams consisted of persons of different profile (independent field experts, e.g. an accounting expert, IT expert, end-user etc.). In spite of the attitude taken not to evaluate the concrete basic technology, some estimation of the computing architecture and functionality was performed, when it was found relevant for the estimation of applicability.

Keywords: ERP software, software capability evaluation, software comparison.

\section{Introduction}

ERP system is an integrated information system to support the business within different organisational parts of an enterprise. International Data Corporation (IDC) defines the ERP software as support for at least three out of the following four business segments [7]: Accounting, Manufacturing, Material management/distribution, Human resources management with payroll.
The term ERP primarily relates to customization and usage of a "ready-made" software package (in further text "ERP package"), and only secondarily relates to software written on purpose for a specific customer. The leading global providers are SAP, ORACLE, BAAN, PeopleSoft and J. D. Edwards. ERP packages are designed to be customizable to concrete needs of an organization and to its legacy systems. The customization of ERP modules for a concrete user is performed with special tools and using specific or standard programming languages. Due to already mentioned general ERP characteristics, customization and implementation usually require specialised knowledge and significant resources [6]. Practical experience and literature agree that this is the crucial part for success [21].

This paper presents the results of an investigation performed in 2001, under the title Comparative Analysis of Information Systems Software in Croatia. It received a grant by the Croatian Ministry of Science and Technology. (GRANT No. 00-146). The focus was set on the comparative analysis of domestic and foreign Enterprise Resource Planning (ERP) software, which is present in Croatia. The aim was to determine:

- the actual contents which is being offered within different solutions,

- the amount of necessary and sufficient investments,

- difficulties and problems connected with implementation of ERP solutions,

- possible effects of application of the implemented solutions, 
- the position of domestic solutions compared to the foreign ones, opportunities of Croatia in this field.

The results of investigation are supposed to inform potential and actual ERP customers about the situation on the market, estimated costs of purchase, implementation, further development and maintenance. The ERP suppliers should get the information regarding the desirable characteristics of these systems, as seen through users' eyes. The final purpose is to give the industry and administration answers to the following questions:

- What can actually be obtained from the solutions available on the market?

- What are the expected costs?

- What development strategies should be chosen?

It is understandable that our investigation paid substantial attention to the existing proprietary ERP solutions developed in Croatia. For the international reader, it may be of less interest, except if regarding Croatia as a paradigm for a small, medium-developed country that has recently passed through an ugly war and not much better privatisation. Although Croatia is better off than most developing countries of the once called Third world, it is plagued by some common troubles as those countries: weak legal system and moderate corruption. Both these weaknesses surely affect the local ERP market.

\section{Method for ERP System Evaluation}

ERP systems are large and complex, so their evaluation is also a very complex task. What is more, there are no generally accepted evaluation methods. Some widely accepted methods [18][19] relate to the evaluation of the software development within an organisation, or concentrate on the choice of supplier of services. Some other investigations performed in different countries were mainly aimed to analyse the market [3][7][8][9].

Therefore, for the sake of this investigation, a proprietary method for evaluation and comparison of ERP systems was defined and elaborated. Essential differences to the known existing procedures are the following:
- Definitions of desirable system characteristics are updated in co-operation with the system suppliers and users alike.

- Evaluation is performed by having insight into the real-life system, rather than by applying questionnaires.

Independent referees perform the evaluation in co-operation with the staff, well acquainted with the evaluated software. In this way, higher objectivity is achieved than by filling-in questionnaires where the suppliers or users "evaluate themselves". Disadvantage of this approach is the increased time required to evaluate a larger number of systems. Practical experience has shown that the evaluation of a single subsystem may take a couple of hours, while to evaluate a whole system can take a week (4-5 working days).

\subsection{Analysis of the Market and Application of ERP Systems}

The preparatory phase consists of:

- Analysis of the world ERP market,

- Identification of ERP package suppliers,

- Identification of domestic ERP package producers,

- Identification of the existing ERP customers,

- Establishing the co-operation with ERP distributors and ERP customers willing to participate in the evaluation.

- Evaluation planning.

\subsection{Definition of the Domain of Analysis and the Working Procedure}

In parallel with the market analysis and location of ERP applications, the definitions are formulated for:

- Desirable subsystems and business functions (ideal ERP system)

- System components to be evaluated,

- Desirable characteristics for evaluation of single ERP components,

- Procedures for evaluation and analysis of results. 
Desirable characteristics and procedures are presented to the suppliers and users of ERP systems. They are encouraged to criticise and they are asked to present their opinion and suggestions to complete the initial material. If during the investigation new relevant characteristics are encountered, they can be added and evaluated.

In other words, the method can be dynamically adapted and enhanced, with the aim that the outcome be the result of the overall knowledge and experience of all stakeholders. To avoid possible contradictory requirements for change, originating from different suppliers and ERP customers, the investigation team withholds the right to accept or dismiss the suggestions.

\subsection{Evaluation Procedure}

During the evaluation phase:

- Evaluation teams for specific business domains are formed,

- The evaluation plan is elaborated and updated for ERP systems and analysed domains,

- Analysis of existing ERP installations is performed.

Evaluation teams consist of a few experts for each analysed business domain. It is desirable that they are experienced users of software in this field, but they need not be computing experts, because only the user's aspect is analysed. It is important that they are experts in the business domain and to increase the evaluation objectivity it is desirable that they originate from different working environments.

The evaluation is performed within an organization with installed ERP. If for some ERP solution such evaluation is not possible, the evaluation can proceed through an insight into the evaluation copy of the software.

The supplier or the customer nominates the "best user", meaning the person who is most familiar with the system capabilities. This user briefly presents the system capabilities, stressing its advantages and features. After preparing the list of desirable characteristics the evaluators ask questions and write down the answers. They give positive marks to those characteristics that can be demonstrated on the computer. If, for any reason, it turns out to be impossible, the evaluation proceeds based upon the available user and/or program documentation. The results and possible additional notes are verified and forwarded to the investigation team for analysis.

\subsection{Evaluation of Capabilities}

For the purpose of evaluation, to each of the capabilities a range of possible marks is adjoined. The lowest mark is zero, denoting that the corresponding capability is not present. The highest mark is set depending on the desired granularity of results. For each capability, its respective importance is quantified by a weight. The lowest weight is unit, while the upper limit also depends upon the desired granulation of the analysis results.

The mark for a system is calculated after the formula:

$\mathbf{O}=\Sigma \mathbf{s}_{i} / \mathbf{m}_{i} * \mathbf{f}_{i}$, for each capability $\mathbf{i}$, where:

$\mathbf{s}_{i}$ is the mark for the capability $\mathbf{i}, \mathbf{m}_{i}$ is the maximum possible mark for the capability $\mathbf{i}$ and $\mathbf{f}_{i}$ is the weight of the capability $\mathbf{i}$.

In the case when the highest mark for each capability equals 1 and if all the weights are equal to 1 , the system evaluation reduces to the sum of capabilities present in the system.

The relative mark for a system $\mathbf{X}$, in proportion to the ideal system $\mathbf{0}$, is calculated as

\section{$\mathbf{R}_{X}=\mathbf{O}_{X} / \mathbf{O}_{0} * \mathbf{1 0 0}$}

An example for possible marks is:

0 - capability is not present,

1 - partly present, available as option,

2 - capability is present,

3 - additional features present,

4 - especially useful capability or a significant innovation.

It is more difficult to define the weights, because the same capability does not have the same importance for various users. It should be left to each supplier and each customer to attach the weights and to use the arithmetical average in the analysis. Alternatively, weights may be proportional to the complexity required to achieve the respective capability. However, the importance of a capability for the user should not be neglected. 
We believe that three weight values are sufficient:

1 - basic functionality,

2 - advanced functionality,

3 - sophisticated functionality.

Regardless of the ranges and weights applied, the analysis and ranking of results can proceed on the level of single components (subsystems) and on the system level, because the capabilities are grouped around various domains.

\subsection{Analysis of Results}

In the last phase:

- A comparative analysis of the gathered results is performed,

- A rank list of ERP solutions is produced,

- The gathered information is synthesized and conclusions are deduced.

\subsection{An Abridged Evaluation Process}

The evaluation by direct insight, if applied for a larger number of systems, might request an excessive engagement of human and financial resources and take too much time. Therefore, an abridged approach is also envisaged.

The method can be modified by decreasing the depth of analysis. For the purpose of evaluation, shortened lists of capabilities are checked. Further simplification evaluates groups of business functions or whole subsystems. Finally, only the existence of groups of functions or subsystems can be checked. Naturally, the quality of analysis decreases with simplifications.

\section{Results of the Comparative Analysis}

\subsection{Analysed Systems and Components}

The call for co-operation within Croatia was addressed to 14 ERP package suppliers and developers and to 10 ERP customers who had purchased an ERP solution or had developed a proprietary system. For the purpose of evaluation, the worldwide known ERP packages present in Croatia were selected. Selection of domestic
ERP products was based on the previous knowledge of the investigation team and completed by references of some IT companies.

The initial response rate to our call for cooperation was $63 \%$, where $38 \%$ participated in preliminary phases of investigation, but only a quarter of them agreed to participate in the evaluation process. It is interesting to mention that the initially high percentage $(63 \%)$ of ERP package suppliers willing to co-operate, significantly dropped during the investigation. At the end, only five systems were analysed: three domestic ones, where two of them had previously been awarded for good quality, and the two leading ERP packages on the world market. Some subsystems were not analysed or not analysed in details, partly because they were not implemented, but also because of limited investigation resources and lack of time. A comparative analysis was performed for the following ERP packages, listed in alphabetic order:

- BAAN, by the BAAN Company, Herndon, VA, USA, at the customer who had been using it for 4 years,

- IS in the company LURA GROUP, Croatia, a proprietary solution,

- SAP, by the SAP A.G., Waldorf, Germany, at the customer who had been using it for 5 years,

- ERP package by the company ENEL d.o.o., Split, Croatia,

- SUPER by the company SUPER-KING d.o.o., Zagreb, Croatia, installation at a representative customer.

We were aware of the diversity of modules within commercially available ERP packages and of the diversity in the organization of those ERP subsystems that were developed on purpose, for known customers. We defined the desirable capabilities, for the components. The evaluation was completed for the following components:

- General characteristics,

- Accounting,

- Manufacturing monitoring,

- Projects monitoring,

- Sales,

- Purchase, 
- Stocks management,

- Manufacturing management,

- Quality control.

For the following components, the evaluation proceeded only partly, i.e. only the existence of components was checked:

- Project management,

- Maintenance management,

- Human resources with payroll.

Three of the evaluated systems comprised all the components, while the rest contained Accounting, Sales, Purchase, Stocks management and Human resources with payroll. All the participants in the investigation had been informed in advance about the evaluation process and received the evaluation forms to be better prepared and to have their say regarding the proposed lists of capabilities. Members of the Croatian Accountants Association joined the investigation team and helped to create the evaluation forms during the preparatory phase.

Respecting the fact that some values may be a confidential, in our call we proposed that the concrete customer and supplier information be hidden, or revealed only after their written permission. Until the end of the investigation, only a domestic company SUPER-KING alowed revelation of its name. All other participants withheld their permissions. We apologise to our readers for having the permission to reveal only one of the analysed systems, while the rest must remain coded. This is partly understandable, because, as stated before, our investigation resources were scarce and, therefore, our concrete findings could even become a subject of litigation.

\subsection{Summary of Subsystems Evaluation}

Table 1 and Figure 1 compare the counts of components within subsystems that were evaluated for capabilities. The last column (Ideal) contains the maximum count of capabilities for each component, representing an ideal system. The last row (Relative system mark) contains the percentage of implemented capabilities in respect to the ideal system.

The systems coded as 10100, SUPER, 10400 have all the components, while for the system 10400 three of them were not evaluated due to objective reasons. Only the systems 10100 and SUPER contain more than half of all desirable capabilities. The system SUPER achieved the best marks and the system 10100 follows. The system 10400 is a complete set of average valued components. The system 10200 achieved very good marks for the components it contains. The system 10500 definitely requires a serious redesign.

\begin{tabular}{|l|c|c|c|c|c|c|}
\hline SUMMARY MARKS & \multicolumn{7}{|c|}{ System } \\
\hline Component & $\mathbf{1 0 1 0 0}$ & $\mathbf{1 0 2 0 0}$ & SUPER & $\mathbf{1 0 4 0 0}$ & $\mathbf{1 0 5 0 0}$ & Ideal \\
\hline Accounting & 67 & 96 & 120 & 58 & 46 & 127 \\
\hline Quality control & 11 & 0 & 23 & 0 & 0 & 23 \\
\hline Purchase & 16 & 31 & 37 & 18 & 15 & 43 \\
\hline General characteristics & 32 & 20 & 58 & 25 & 14 & 61 \\
\hline Sales & 46 & 51 & 66 & 18 & 21 & 67 \\
\hline Manufacturing management & 105 & 0 & 168 & 88 & 0 & 173 \\
\hline Stocks management & 22 & 17 & 32 & 12 & 10 & 34 \\
\hline Manufacturing monitoring & 13 & 0 & 12 & 0 & 0 & 14 \\
\hline Projects monitoring & 15 & 0 & 13 & 0 & 0 & 15 \\
\hline Summary system mark & $\mathbf{3 2 7}$ & $\mathbf{2 1 5}$ & $\mathbf{5 2 9}$ & $\mathbf{2 1 9}$ & $\mathbf{1 0 6}$ & $\mathbf{5 5 7}$ \\
\hline Relative system mark & $\mathbf{5 8 . 7 1 \%}$ & $\mathbf{3 8 . 6 0 \%}$ & $\mathbf{9 4 . 9 7 \%}$ & $\mathbf{3 9 . 3 2 \%}$ & $\mathbf{1 9 . 0 3 \%}$ & $\mathbf{1 0 0 \%}$ \\
\hline
\end{tabular}




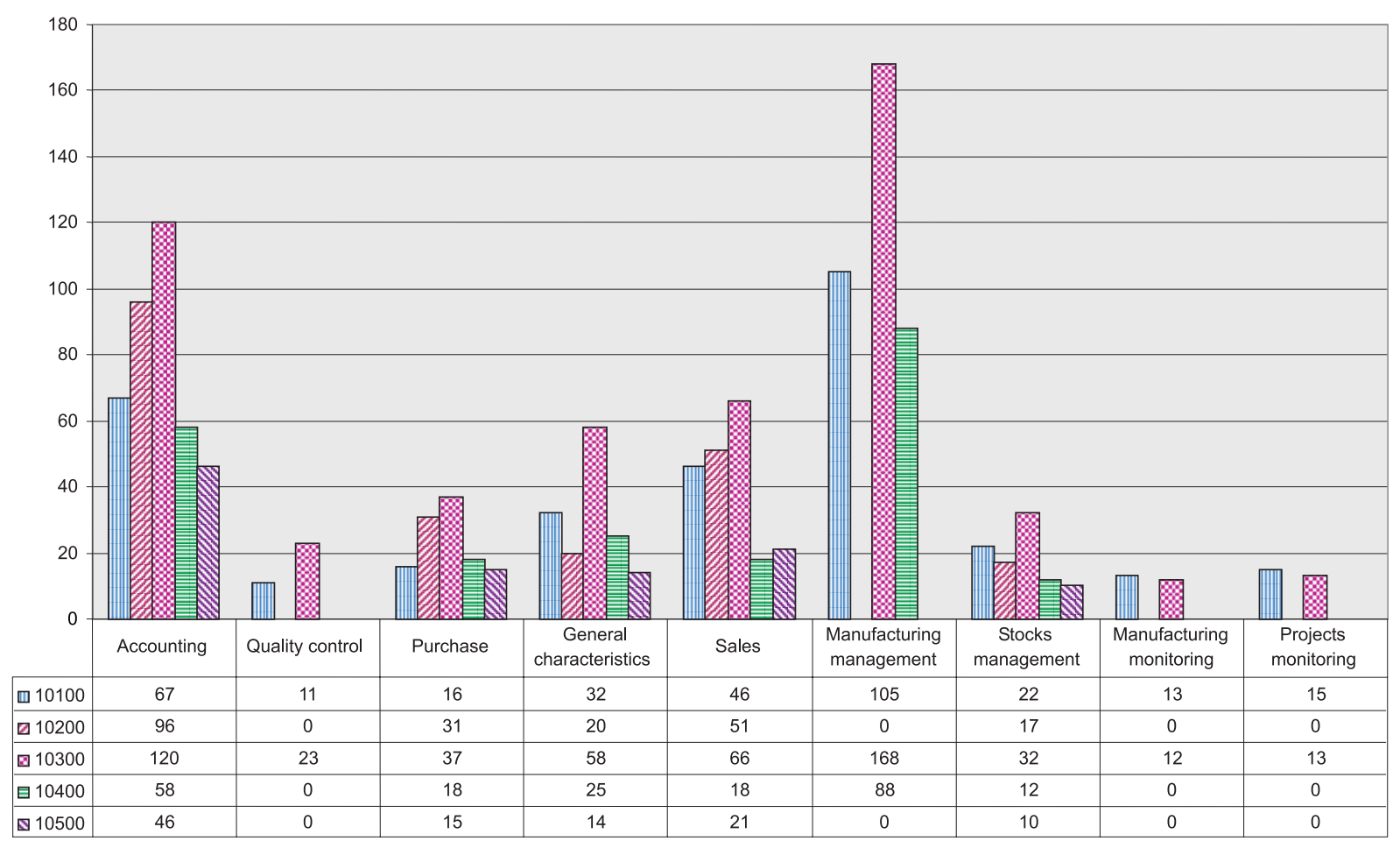

Figure 1. Summary marks of ERP packages.

\subsection{Relative Mark Values}

Table 2 and Figure 2 represent the relative presence of capabilities compared to the ideal system. The last column contains the average value of the examined ERP systems. The last row presents the average components mark.
On average, Accounting and Sales are best supported. Purchase and Stocks management follow the suit, but their completeness is only slightly above $50 \%$. General characteristics hardly reach half of the Ideal system. Supports to the Manufacturing and to the Quality control are the weakest points.

\begin{tabular}{|l|c|c|c|c|c|c|}
\hline RELATIVE MARKS & \multicolumn{7}{|c|}{ System } \\
\hline Component & $\mathbf{1 0 1 0 0}$ & $\mathbf{1 0 2 0 0}$ & SUPER & $\mathbf{1 0 4 0 0}$ & $\mathbf{1 0 5 0 0}$ & Average \\
\hline Accounting & $52.76 \%$ & $75.59 \%$ & $94.49 \%$ & $45.67 \%$ & $36.22 \%$ & $60.94 \%$ \\
\hline Quality control & $47.83 \%$ & $0.00 \%$ & $100.00 \%$ & $* 4.35 \%$ & $0.00 \%$ & $30.43 \%$ \\
\hline Purchase & $37.21 \%$ & $72.09 \%$ & $86.05 \%$ & $41.86 \%$ & $34.88 \%$ & $54.42 \%$ \\
\hline General characteristics & $52.46 \%$ & $32.79 \%$ & $95.08 \%$ & $40.98 \%$ & $22.95 \%$ & $48.85 \%$ \\
\hline Sales & $68.66 \%$ & $76.12 \%$ & $98.51 \%$ & $26.87 \%$ & $31.34 \%$ & $60.30 \%$ \\
\hline Manufacturing management & $60.69 \%$ & $0.00 \%$ & $97.11 \%$ & $50.87 \%$ & $0.00 \%$ & $41.73 \%$ \\
\hline Stocks management & $64.71 \%$ & $50.00 \%$ & $94.12 \%$ & $35.29 \%$ & $29.41 \%$ & $54.71 \%$ \\
\hline Manufacturing monitoring & $92.86 \%$ & $0.00 \%$ & $85.71 \%$ & $* 7.14 \%$ & $0.00 \%$ & $37.14 \%$ \\
\hline Projects monitoring & $100.00 \%$ & $0.00 \%$ & $86.67 \%$ & $* 6.67 \%$ & $0.00 \%$ & $38.67 \%$ \\
\hline Average component value & $\mathbf{6 4 . 1 3 \%}$ & $\mathbf{3 4 . 0 7 \%}$ & $\mathbf{9 3 . 0 8 \%}$ & $\mathbf{2 8 . 8 6 \%}$ & $\mathbf{1 7 . 2 0 \%}$ & $\mathbf{4 7 . 4 7 \%}$ \\
\hline
\end{tabular}

\footnotetext{
* For the system 10400 only the existence of subsystem was taken into account.
} 


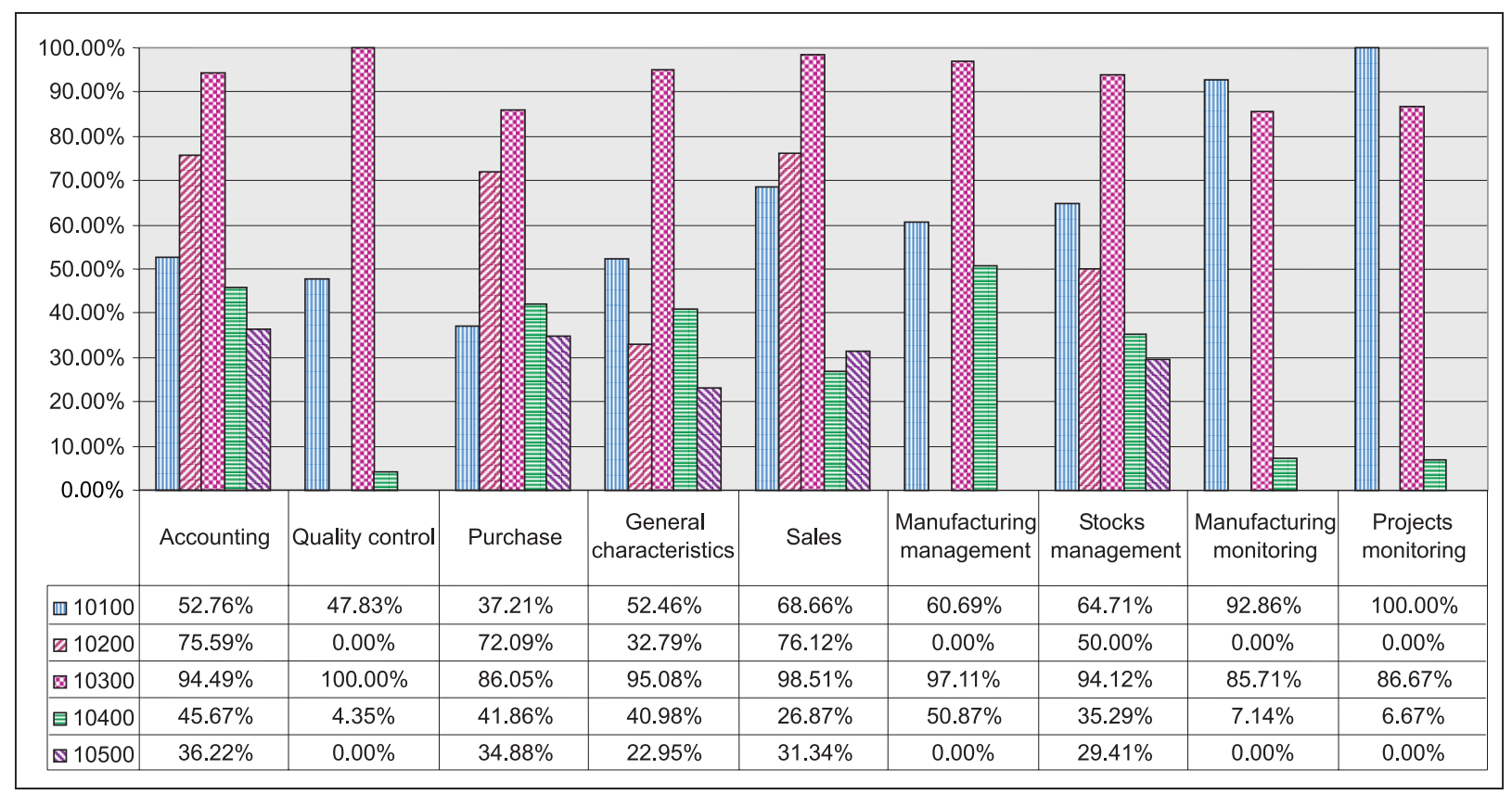

Figure 2. Relative marks of ERP packages.

\section{Summary of the Analysis of the Leading Foreign ERP Packages}

After a detailed analysis of the ERP packages used in Croatia (SAP and BAAN) and after acquiring a partial insight into the software and available documentation for the packages by ORACLE, J. D. Edwards and PeopleSoft and after an additional review of the literature published worldwide, we came to the following conclusions:

- ERP packages are technologically modern, comprehensive and reliable software.

- They cover many business domains.

- They support more than a thousand business functions or working procedures.

- They support many variants of business procedures.

- They support the operational parts of business procedures, i.e. everyday transactions which generate data.

- They are based on modern technologies (multy-tier client/server architecture, OLE, HTML, SMTP, MAPI, EDI, ALE,...).

- Although there are sporadic objections to their reliability, they perform at least so well as the proprietary customer designed solutions.

- ERP packages are sets of interconnected partial solutions, rather than integrated solutions.

- They had initially been developed to support a certain function (e.g. Accounting, Manufacturing) and other modules were added afterwards.

- Single modules or subsystems had been developed in different software companies and were acquired by the owner of the "integral" ERP package later. These acquired subsystems are interconnected in different ways (common database, data transfer, and even manual data entry from one module to the other).

- Within single subsystems, the variants for some business functions coexist as partial solutions, mostly without any generalisation.

- Functional quality and sophistication of implemented solutions is mediocre.

- They principally support everyday transactions with a low level of analytic reporting. 
- Sophisticated functions, like optimization or simulation, are mostly absent and they are substituted by combinations of more complex queries and reporting.

- ERP packages are very large and inefficient.

- The software dwells over huge databases and the program code is huge. For example, SAP handles 14,000 tables, there are 650 fields to describe a material, and PeopleSoft contains 14,000 predefined screen forms.

- An average customer uses only a small fraction of the features available, so the major part of the system is a useless burden in application and maintenance.

- Software was principally designed for efficient transaction processing and simple reporting. Due to the large number of highly normalized tables, more sophisticated reporting is resource consuming.

- ERP packages are complex and rigid for implementation and maintenance.

- Implementation and customization require non-standard fourth generation languages and specialised routines for transaction handling.

- The systems have been designed as a large set of predefined functions, rather than easily customizable solutions.

- Accordingly, the customer is sometimes forced to change the organization and business procedures to adapt to the software.

- The system administration requires knowledge of a large number of parameters and procedures, which are described in manuals of more than thousand pages.

- Customization and implementation are timely and complex. They comprise the following activities:

- Definition of the customer's information requirements.

- Definition of input and output for the information system.

- Identification of those embedded components, which are useful to the customer. This is usually a small fraction of the package. Retrieving of the desired data structure and desired function is difficult because of the large number of predefined items.

- Design and customization of the datahandling screen forms.

- Implementation of advanced reporting, because only simple ones are at hand [24].

- Lack of the basic reporting system can be solved in the following ways:

- ERP database is used and only reporting modules are added. Reporting slows down the system and assignment of lower priority to reporting can be a remedy. An example is SNAPpack by Information Builders, New York, applied for reporting from the leading ERP packages (SAP, J.D. Edwards and PeopleSoft).

- ERP database is copied on another medium and the reporting proceeds from there. For example, EMC Corp., Massachusetts, offers a hardware and software solution called Time Finder, to create a copy of the database on a separate server. It is used for reporting, but also as a backup for the database.

- Data from the ERP base are written into a differently structured new database. It is the most common Data Warehousing approach where usually separate hardware is used.

- Combination of the above solutions, where some reports are generated by additional programs from the ERP database and some other come from a separate system containing the copy. An example is Crystal Decisions, by Seagate Software, which generates reports from ERP systems and from the Data Warehousing systems.

- Regardless which of the above procedures is applied, copying of ERP data into spreadsheets (e.g. MS Excel) is most usual.

- ERP packages are not a stable basis to develop an information system:

- Soon after the purchase and at the latest after three years, the pressure of the supplier to buy a new version intensifies. 
It is sometimes enforced with the threat that any support to the existing version will cease otherwise [13].

- Due to all the considerations enumerated above we find that the mentioned, world renown ERP packages do show some serious disadvantages:

- The structure of these systems had not been designed on purpose, it had "happened" through time, as sediments of (acquired) subsystems and partial solutions.

- They are difficult to understand, to implement and to maintain [6].

- They require constant consulting.

- They excessively consume the computing resources.

What a customer really gets with an ERP acquisition is the contents and structure of the database and a large number of partial solutions to support the operational functions, which may, but need not, comprise the solutions the customer really needs. The missing functionality is repaired with additional components (socalled concepts) like Customer Relations Management (CRM), Supply Chain Management (SCM), Application Link Enable (ALE), Data Warehousing and Data Mining. To the set of all these partial solutions a preposterous name best of breed is given. Unfortunately, instead of an integral system, based on a solid concept, addons are applied leading to fragmentation, they increase complexity and inefficiency of the information system.

- In spite of all the setbacks and much criticism addressed to the famous ERP systems, our informal sources of information, which unfortunately cannot be properly documented, lead us to a speculation that the market accepts them for the following reasons:

- The number of predefined functions is so large that it leaves the potential customer with the impression that within the package "all has been solved". However, much effort to reach full functionality and applicability is required.

- ERP suppliers impress the potential customers with the numbers of existing installations and reference lists with most famous world companies.
- Significant knowledge and experience has been gathered and embedded during yearslong existence of some ERP packages.

- The customer tries to compensate the lack of own IT personnel by hiring so called "Certified consultants" who in some cases, informally but accountably reported to us, achieve that title regardless of the previous education and after only a short training.

- In industrialized countries, the massively "produced", meaning cheap, semi-qualified but highly specialised work force provides the customization of the package fragments.

- As the initial investment represents about a third of overall costs, the ERP costs may appear lower than a proprietary development.

- Customers are exhausted by technological progress in IT and they like to delegate the problem to ERP suppliers.

- While integrating islands of computerisation, to avoid internal arguments whose solution should prevail, an ERP package is acquired as a neutral solution.

- If you buy the "world's best" solution, you do not get fired.

- Some customers who have dearly paid for their ERP do not dare to admit failure.

- In some developing countries, big investment may imply big bribe.

- In developing countries, the loans from highly developed world mostly have to be spent on purchases back from the same highly developed world. Therefore, "world-renown" consulting companies are engaged who favour "worldrenown" ERP products and "ready-made" solutions, regardless how low is the possibility to implement them locally. Most of the money returns to the highly developed world, local elites enjoy some fraction of it, the project often fails and in the years to come the poor population pays back the loan increased by interest rates. According to the Croatian daily press, the need to rely on local expertise 
in order to succeed has recently been admitted by the World Bank's President Mr. Wolfensohn.

\section{Position of Local Solutions in Respect to the Leading ERP Packages}

We found that good proprietary ERP solutions exist in Croatia. According to the results of our investigation 2 out of 3 examined ERP systems are comparable or in some (at least locally appreciated) aspects even better than the world renown packages.

Logically, there are not many local ERP packages on the market, especially having in mind that development of such software takes hundreds of person-months, or even person-years. However, there are a few other good Croatian packages, which were not evaluated in this study.

General characteristics of these locally produced and favourably evaluated ERP packages:

- They are offered as complete solutions encompassing complete customer requirements, with prepared screen forms and reporting systems.

- Practically no customization is required for the implementation. Some organizational measures and education of users are the only requirement.

- They are compact and homogenous, because they do not consist of acquired and later interconnected components.

- They are implemented much easier and are much cheaper.

- They have a very weak marketing.

- They find it very difficult to follow the technical advancements.

\section{Opportunities for Improvement}

\subsection{Situation in Croatia}

According to the available data and some previous investigation, the situation can be described in following statements:
- The majority of existing information systems are technologically obsolete or do not correspond to the customer's needs.

- After the initial boom, where most of those who had some money bought a renowned ERP, the ERP market has shrunken. It can be attributed to political changes, increased caution and lack of money [9].

- The Croatian market potential is estimated on 300-400 larger customers and many small and medium size (with 10 or more employees) companies [9].

Apart from the above-mentioned exceptions, the main characteristics of most other domestic products are:

- Incomplete solutions: Most domestic companies do not offer an integral solution. Usually they are only partly integrated and cover only certain domains, usually Accounting, Materials handling and Human resources with payroll.

- Inadequate solutions: Software developed 10 years ago is obsolete now. Some domestic companies, specialised for domains like banking or insurance, tend to widen their activity as outsourcers, regardless of their (in)competence in new domains.

Main setbacks of acquisition of foreign ERP packages are:

- World market prices are too high for local conditions. Very high initial investments are necessary. It would be fair that the foreign vendors adapt their pricing policies to the local per capita BDP. It might be not applicable for the foreign consultants' fees, but for the price of licences, it should be feasible. Such policy would reduce the differences in benefit of buying an ERP system between highly developed countries on one side and those less developed on the other.

- Incompatibility of foreign solutions with local conditions, resulting in significant customisation and organizational efforts [20]. A hidden cost caused by higher restructuring efforts in less developed world remains, but it would be too much to expect from ERP vendors to cater for that.

- Big discrepancy between the price of the basic product $(30-40 \%$ of the overall costs) 
compared to the customization costs $(60$ $70 \%$ of the overall costs).

- Too long period of implementation for a "ready-made" solution. It may take from one to three years and after 3-4 years, a new development cycle is already due. Some implementations extend even longer and/or the required functionality is never achieved.

- Long-term dependency upon the supplier and expensive consultancy. Fees of 1,2001,800 USD per day are paid for a consultant, which exceeds a good local monthly salary.

- Occasional incompetence of (especially some foreign) consultants and instability of suppliers. Poor treatment of customers by the ERP producers derives from the perception that Croatia is a small and unimportant market where third class consultants can be sent. On the contrary, more knowledge is often required in such a country than in a highly organized one.

\section{Cost and Benefit}

Depending on the field of their activity, potential customers can count on some usual positive effects of computerization [12]:

- integration of financial data,

- standardization of human resource data,

- standardization of business processes,

- standardization of manufacturing processes.

In USA, an average investment in a project amounts to 15 million USD, average end-user costs are up to 53.320 USD and return of investment can be expected after 31 months, at the earliest [12]. Additional costs of support after implementation amount to 2,304 USD per user in large organizations and up to 7,870 USD for the small ones [15]. It is not always easy to determine whether the investment in computerization pays off [14][16][22], but there is a general awareness that a company not investing in its information system would be out of business very soon.

Domestic software is much cheaper. A representative product can be bought for 2.350 USD per workstation, with one-year guarantee and support. General cost benefit analysis was not possible, because the necessary data have not been revealed.

It is nearly impossible to estimate in advance some hidden costs like:

- educational costs including the adaptation of users to new working ways,

- integration and testing, which is difficult to foresee, depending upon the connection with legacy systems,

- data conversion often represents an unpleasant surprise, due to un-normalized relations or inadequate codification in legacy systems,

- data analysis becomes costly if the ERP data need to be combined with data from other sources,

- protracted engagement of consultants,

- unexpected efficiency decline as the staff cannot proceed in the usual way.

The cost of owning an enterprise-wide application goes far beyond an application's purchase price.[1]. The largest costs result from implementation efforts. Failed efforts have brought some companies to sue the ERP supplier [4].

\subsection{Proposal for IS Development Policy}

\section{Recommendations to Customers and Users}

Potential customers should perform the following actions:

- Estimation whether the intended ERP purchase really corresponds to their requirements [5][2].

- Market-oriented complex companies who tend to be and stay in some way specific and recognizable and wish to maintain the edge over competition should rely on some proprietary development, at least for support of their highly competitive functions.

- Manufacturing companies should consider the applicability of the offered readymade solutions. For example, productionplanning approach heavily depends on the type of manufacturing: assembly industry versus high series or continuous production, assembly tables versus production processes descriptions [11] etc. 
- Cost benefit analysis, especially the ratio between adaptation of business procedures to software versus the costs of software adaptation to business processes.

- Definition of appropriate metrics for outsourcers/consultants, where their results should prevail over their physical presence.

- An additional criterion to evaluate the outsourcers can derive from independent testing of the staff ability to use the implemented solution.

- Definition of metrics to evaluate and manage own IT staff, which includes:

- education and maximum usage of internal human resources,

- awards according to successful implementation,

- readiness to changes in staff, in order to substitute overpriced employees,

- avoiding of possible blackmails and misuse after the implementers get acquainted with the weak points of the company,

- Assurance of acceptability for solutions delivered from outsourcers, achieved by precise contracts, definition of acceptance tests and major payments only after successful implementation.

- Planning of implementation and maintenance, including feasibility studies and risk management.

- Establishing of a pilot project or installation to prove the functionality.

- Estimation of alternative strategies:

- Simultaneous implementation, so called Big Bang requires excessive efforts; it often fails and it should be avoided.

- Franchise Strategy comprises the installation of independent subsystems with integration only in their common process (e.g. in Accounting).

- Slam-dunk strategy is oriented to some crucial business processes. It is convenient for smaller companies that are not ready to invest in comprehensive ERPs.

Information system owners who have just completed the implementation cycle or who intend to start a new cycle should perform:
- System quality analysis.

- Revision of the computerization project.

- System cost benefit analysis.

Regardless of the customer type, we suggest:

- Engagement of independent consultants, especially if an impartial quality analysis is required.

- Engagement of independent (third party) outsourcers for support and maintenance, if applicable.

- Establishing of at least a minimum local IT expertise. Local experience has shown that ERP installations became successful after local expertise had been gained.

- The most important aspect is the proper motivation and high commitment of the top management. Establishing of an information system cannot be completely purchased nor delegated. It cannot be introduced by brute force, because there are too many possibilities to compromise the project if it is perceived as being against some of the stakeholders' interests [10].

\section{Recommendations to ERP Suppliers and Developers in a Developing Country}

In addition to some widely recognized measures [17] suppliers-representatives of foreign ERP solutions should:

- In a country with moderate to high corruption, resist the temptation to apply bribery as a shortsighted method, which should backfire eventually.

- Increase the quality of support and customization instead of pure reselling.

- Educate local consultants instead of relying on foreign ones who are expensive and often inept to understand the local conditions.

- Include local experts in the development and customization.

- Negotiate joint approach to third markets.

- Adapt the licence price to the local per capita BDP. 
- Forward users' remarks to the software producers to improve the quality and customers' satisfaction.

- Accept that major payment is due after the user-acknowledged functionality has been achieved.

Domestic developers should:

- Technically update and complete the existing applications.

- Offer application hosting and provide application services as soon as possible.

- Direct themselves towards small and medium size customers.

- Direct themselves towards specialized software, which is not present in major ERPs.

\section{Conclusion}

The response rate in this investigation left us with an impression that domestic companies are mostly uninterested in improvements, which is rather strange, considering the potential of current unsatisfactory state of computerization in the country. The suppliers of ERP solutions, who trust their products, accepted the challenge of evaluation and so did the customers who do have some achievements but who are also aware of the deficiencies in their systems.

The leading world-renowned ERP packages are technologically modern, comprehensive and reliable software. The functional quality and sophistication of the implemented software is however surprisingly mediocre. Customization and implementation of a "ready-made" solution can extend through years, creating a large discrepancy between the price of the basic product and the costs of customization. The main reason for high costs is the necessity that, simultaneously, the software needs to be adapted to the organization and the organization and the business processes have to be adapted to the ERP package. The weakest point might be the consultants who often lack the knowledge about their complex ERP system and, on the other hand, they lack experience in information systems development and do not understand the target system. The presumed, and in ERP systems embedded high level of organization and obedience to the rules, cannot always be respected in developing countries. Potential ERP buyers should count on a dependency upon the supplier and on expensive consultancy for a long time. Reliance upon a pool of own experts might be the best solution in a country with relatively low salaries.

The main characteristics of domestic ERP products, with few exceptions, are incompleteness and inadequacy and/or technical obsolence.

Best solutions can be found for Accounting, Human resources and Payrolls. Material handling is less present. Support for manufacturing is lacking. On the other hand, investigation has detected some cheap local solutions, which could in a fair competition challenge, according to locally appreciated functionality, the worldrenowned products.

Regardless whether an information system is bought or developed, computerization should lead to the integration of data and to standardization of business processes. The total price for a certain customer can hardly be properly forecasted. Many hidden costs must be taken into account. The largest cost results form possible failure or even worse, protracted efforts in a failed project.

Software development is work intensive. The price of human work in highly developed countries can be up to 10 times higher than in a medium developed country like Croatia. For the latter countries, price performance ratio of their proprietary solutions can be more acceptable than in highly developed countries. Worldrenowned ERP solutions are aimed for highly organized societies. The assumption that introduction of such systems into less developed environments would introduce order and discipline and improve organization, may sound plausible but it is not necessarily true. If the gap is too wide, the failure is granted. Without investment in local expertise, the technology gap only widens. Our suggestion for countries like Croatia is not to expect that wonderful solutions can be simply bought. Own effort is indispensable and only this can make such countries respected partners on the world market.

We cannot offer a clear answer to an intriguing question, whether to buy an expensive renowned ERP or a cheaper domestic counterpart. A complex ERP might take too much effort and time to implement. Domestic product can be put into 
function quicker and requires less restructuring. When, with time, the user finds the functionality of such a system unsatisfactory and the deliverer cannot meet the growing requests for enhancement, it might be the right time for acquisition of a renown ERP. In such case acceptance should proceed easier and quicker. Which approach is more favourable has to be deliberated on case by case basis.

It is natural that any less developed country tends to become part of the highly developed world. Pure reliance on foreign expertise can make only standing dependency and maintain, or even widen the gap. Illustrative is the example of the Republic of Korea. It could not make a substantial progress regardless of its successful electronic industry as long as it was dependant on foreign supplies. The better the Korean final products were sold, the more expensive became the imported inputs. When Korea took over the expertise, it became a well-known success story $[25]$.

\section{References}

[1] Applix Enterprise, Total Cost of Ownership Study for Enterprise Applications, white paper, Applix. Inc, 2000.

[2] R. B. CAMPBell, ERP: Show me the Money!, Axislogic Consulting Inc., 2001,

http://www.axislogic.com/erpstory.htm

[3] Ernst \& Young and uni Wien, Optimierungsbedarf von ERP-Software in Österreich, Ernst \& Young Unternehmensberatung Ges.m.b.H und Institut für Kreditwirtschaft an der Wirtschaftsuniversität Wien, Vienna, 1999.

[4] S. GoodwIN, Software Risk Management Makes Good Business Sense, http://www.stickyminds.com/sitewide.asp ?Object Id=2663\&Functi on=DETA ILBROWSE\& Object Type=ART, 2004-07-06.

[5] B. HECHT, Choose the right ERP software, Datamation, 43(3), pp. 56-58.

[6] P. C. Holland, B. Light, A Critical Success Factors Model for ERP Implementation, IEEE Software, 16(3), pp. 30-36.

[7] IDC, The Integrated Enterprise Application (ERP) Market in Croatia, IDC East Central Europe, Praha, 1998.

[8] IDC, Management Summary, 1999 Croatian ERP Market, IDC East Central Europe, Praha, 1999.
[9] IDC, The Integrated Enterprise Resource Management Software Application Market in Croatia, 1999-2004, IDC East Central Europe, Praha, 2000.

[10] D. Kalpić, K. Fertalu, V. Mornar, Analysis of Reasons for Failure of a Major Information System Project, BITWorld 2001 Conference Proceedings, CD-ROM, ISBN 090530436 5, Kamel, Sherif (ed.). Cairo: The American University in Cairo, 2001, pp. 1-8.

[11] D. Kalpić, M. Baranović, V. Mornar, Case Study Based on a Multi-Period Multi-Criteria Production Planning Model, European Journal of Operational Research 87, (1995), pp. 658-669, Elsevier Science B. V., Netherlands.

[12] C. KOCH, The ABCs of ERP, 2002. http: //www. cio.com/research/erp/edit/ erpbasics.html

[13] M. Levinson, Let's Stop Wasting \$78 Billion a Year, CIO Magazine, 15.10.2001.

http: //www. cio.com/archive/101501/ wasting.html

[14] A. C. Macada, M. A. Mahmood, J. L. BecKer, Development and Validation of an Instrument to Evaluate the Impact of Information Technology Investments: A Cross-Country Analysis, Presented at the IRMA 2000 - Challenges of Information Technology Management in the 21st Century, (May 21-24, 2000) Anchorage, AK, USA, pp. 893-896.

[15] METAGROUP, A Platform-Related Cost Analysis of ERP Applications on-Going Support Costs in the Mid-Tier, MetaGroup Consulting, 11. February 2000.

[16] M. A. MAHMOOD, Amerireal Corporation: Information Technology and Organizational Performance", Presented at the IRMA 2000 - Challenges of Information Technology Management in the 21st Century, (May 21-24, 2000) Anchorage, AK, USA, pp. 1037-1038.

[17] A.-W. SCHEER, F. HABERMANN, Enterprise resource planning: making ERP a success, Communications of the ACM, 43(4), pp. 57-61.

[18] SEI, Software Capability Evaluation Version 3.0 Method Description CMU/SEI-96-TR-002, Software Engineering Institute, Carnegie Mellon University, Pittsburgh, Pennsylvania, 1996.

[19] SEI, Software Capability Evaluation Version 3.0 Implementation Guide for Supplier Selection CMU/SEI-95-TR-012, Software Engineering Institute, Carnegie Mellon University, Pittsburgh, Pennsylvania, 1996.

[20] C. SOH, S. S. KIEN, J. TAY-YAP, Enterprise resource planning: cultural fits and misfits: Is ERP a universal solution?, Communications of the ACM, 43(4), pp. 47-51.

[21] T. M. Somers, K. Nelson, The Impact of Critical Success Factors across the Stages of Enterprise Resource Planning Implementations, Proceedings of the 34th Hawaii International Conference on System Sciences, (2001), Hawaii, USA. 
[22] C. STEDMan, What's Next for ERP?, Computerworld, 33 (1999), pp. 48-49.

[23] C. Stedman, ERP projects cost more than their 'measurable' payback, Computerworld, (Online News, 03/29/99 06:29 PM).

[24] J. ZYGMONT, ERP system performance - rethink reporting, Datamation IT management Update, 19.5.1999.

[25] *** Invited lecture of a Korean expert on the $18^{\text {th }}$ International Conference on Computers \& Industrial Engineering, ICC\&IE'95, Shanghai, China, October 25-27, 1995.

Received: February, 2004

Revised: July, 2004

Accepted: August, 2004

Contact address:

Krešimir Fertalj

Faculty of Electrical Engineering and Computing

University of Zagreb

Unska 3

10000 Zagreb

Croatia

Phone: +38516129918

Fax: +38516129915

e-mail: kresimir.fertalj@fer.hr

Damir Kalpić

Faculty of Electrical Engineering and Computing

University of Zagreb

Unska 3

10000 Zagreb

Croatia

Phone: +38516129919

Fax: +38516129915

e-mail: damir.kalpic@fer.hr
KREŠIMIR FERTALJ is an assistant professor at the Department of Computer Science of the Faculty of Electrical Engineering and Computing, University of Zagreb, Croatia. He graduated and received his M.Sc. and $\mathrm{Ph} . \mathrm{D}$. degrees in computing from the same institution. Since graduation in 1988, he has been working at the Department of Applied Mathematics, where he currently lectures a couple of undergraduate and postgraduate courses in computing. He also held courses in data modelling, information systems development and fourth generation languages. His professional and scientific interest is in computer-aided software engineering and complex information systems. He has defined a proprietary software development method based on iterative prototyping and, based on it, developed a proprietary source code generator. He ran a few projects supported by the Croatian Ministry of Science and Technology. Currently he is the principal researcher on two such projects, "Improvement of Information System Development Methods" and "Business Information System Feasibility". He has authored and co-authored many scientific and professional publications and participated in conferences, locally and abroad. Professionally, he participated in a dozen information system projects for business, industry and administration.

DAMIR KALPIĆ received his Ph.D. degree in 1982 in computer science from the Faculty of Electrical Engineering, University of Zagreb. Since 1971 he has been working in the same institution, nowadays called Faculty of Electrical Engineering and Computing. He is full professor, teaching information systems and software-related courses in undergraduate and postgraduate studies. He has mentored more than 180 graduation theses, and a number of M.Sc. theses and doctorates. He has written over 160 texts and R\&D papers, mostly reflecting practical implementation of IT in many different fields. He is the senior member of the R\&D team at the Department of Computer Science. Together with his colleagues, he has completed more than 10 complex projects accepted in practice by industry and administration. They cover information systems development, operational research applications and databases. He was the deputy dean and vice dean, editor of the CIT Journal and member of many international programme committees. For eight years he was chairing the International Programme Committee of the Conference "Information Technology Interfaces". 